\title{
TRADUZINDO AS MENINAS DE BALTHUS
}

\author{
Rosana Kohl Bines* \\ Pontifícia Universidade Católica do Rio de Janeiro
}

\begin{abstract}
Resumo: Por que tentar escrever algo que é irredutível a outra forma de expressão? A pergunta aparece ao final de um conto notável do escritor brasileiro Sergio Sant'Anna, que descreve nos pormenores uma série de telas do pintor franco-polonês Balthasar Balthus, em que figuram meninas-mulheres em poses ambíguas, entre inocência e lascívia. O presente artigo investiga processos tradutórios entre pintura e literatura, a partir do topos da infância, considerado como zona liminar, operadora de passagens entre silêncio e linguagem. Para tanto, traça um itinerário reflexivo que parte da teoria freudiana sobre a afasia.
\end{abstract}

Palavras-chave: Tradução. Infância. Afasia. Ekphrasis.

\section{TRANSLATING THE GIRLS OF BALTHUS}

\begin{abstract}
What is the point in trying to write something that is irreducible to another form of expression? The question appears at the end of a noteworthy short story by the Brazilian writer Sergio Sant'Anna, which painstakingly describes a series of paintings by the Polish-French artist Balthasar Balthus. These paintings depict young girls in ambiguous poses, between innocence and lusciousness. The present paper investigates
\end{abstract}

* Formação em Letras (Português/Inglês e Literaturas), Pontifícia Universidade Católica do Rio de Janeiro. Mestrado em Letras, Universidade Federal do Rio de Janeiro. Doutorado em Literatura Comparada, Universidade de Chicago. Pós-Doutorado em Letras, Pontifícia Universidade Católica do Rio de Janeiro. Professora Adjunta do Departamento de Letras da Pontifícia Universidade Católica do Rio de Janeiro. Rio de Janeiro, Rio de Janeiro, Brasil. E-mail: rkbines@ gmail.com 
translation processes between painting and literature, through the topos of childhood, taken as a borderline zone and a passageway between the domains of silence and of language. To that end, the paper traces an intellectual itinerary that stems from the Freudian theory on aphasia.

Keywords: Translation. Childhood. Aphasia. Ekphrasis.

\section{Introdução}

No livro Ecolalias - sobre o esquecimento das línguas, o pesquisador norte-americano Daniel Heller-Roazen (2010) persegue a hipótese, aberta pelos primeiros estudos da afasia realizados por Roman Jakobson e Sigmund Freud, de que o processo de aquisição de uma língua específica pela criança se dá ao preço de um ato radical de esquecimento. Entre os balbucios do bebê, que contém um potencial de vocalização fônica ilimitada, e as primeiras palavras da criança, não haveria uma passagem gradual, mas uma interrupção decisiva. Algo que Giorgio Agamben (2005) também descreve em sua obra como um salto para a língua, uma cisão radical entre phoné e logos, entre voz e razão, entre sons erráticos e linguagem articulada - uma fratura que funda a experiência humana sob o crivo da privação e da descontinuidade.

Mas o que acontece neste intervalo aos muitos sons que a criança produzia e qual o sentido desta capacidade que possuía de uma infinita vocalização indiferenciada, se esta será tão precocemente descartada no aprendizado de uma língua específica? A nova língua materna se apodera do novo falante de tal forma, que não admite resquício algum de outras línguas? O bebê precisa esquecer a série ilimitada de sons para conseguir dominar o sistema fônico finito de uma só língua? E as nossas línguas adultas guardariam algum resíduo da emissão desordenada da qual surgiram? Ao levantar estas questões, Heller-Roazen explora, ao longo de seu livro, variadas formas literárias daquilo que chama de ecolalias, elucidando nos textos estudados os ecos de outra fala esquecida, vestígios que guardariam a memória do balbucio indistinto e imemorial que, ao ser perdido, possibilitou que todas as línguas existissem, tornando a tradução um dispositivo incontornável da experiência humana. 
Parte-se deste entroncamento específico entre infância e tradução para acompanhar mais amiúde a leitura que Heller-Roazen faz do dispositivo da tradução nos estudos de Freud sobre a afasia e para derivar dali uma rota de aproximação ao conto do escritor brasileiro Sergio Sant'Anna, intitulado "Contemplando as meninas de Balthus" do livro $O$ Vôo da Madrugada de 2003. Este conto integra uma trilogia, agrupada ao final do livro sob a rubrica "Três textos do olhar", forjados na tradição da ekphrasis, da descrição verbal de obras plásticas. No conto específico de que trataremos, a infância é o material figurativo que deverá ser transposto das telas do pintor franco-polonês Balthasar Balthus para as páginas do livro. Interessará observar como os movimentos narrativos em direção à infância nos quadros geram uma reflexão contundente sobre a infância da linguagem, sobre a irrupção súbita das palavras, sua realidade material na página, tornada atual e palpável nos embates tradutórios entre palavra e imagem, entre o dizível e o visível.

\section{Sobre a afasia}

Acompanhemos a reconstituição que Daniel Heller-Roazen faz do pensamento de Freud no ensaio Zur Auffassung der Aphasien: Eine Kritische Studie (Sobre a concepção de afasia: um estudo crítico), publicado em 1891 em Viena (Cf. FREUD, 2003). Como esta primeira obra publicada de Freud não fora incluída em suas obras completas, este pequeno livro de cerca de 80 páginas permaneceu num certo limbo acadêmico, tendo sido até hoje muito pouco estudado. A tese principal de Freud neste estudo, na paráfrase competente de Heller-Roazen, é a de que a afasia é um fenômeno que não pode ser explicado apenas por meio de uma referência direta a uma localização cerebral, como afirmavam até então os estudos de Paul Broca, divulgados em 1861, para quem os distúrbios da fala poderiam ser circunscritos a uma lesão específica do hemisfério esquerdo do cérebro. 
Contra estas tentativas de reduzir as questões da fala a regiões específicas do córtex, subsumindo os processos psíquicos ao campo fisiológico, Freud avançou a hipótese de que o aparato lingüístico ocupa uma região cortical contínua, de modo que quando uma ideia vem à consciência, deslancha no cérebro um processo que começa em um ponto específico do córtex, mas logo irradia por toda a superfície cortical em inúmeras ramificações. Tal estrutura estratificada do aparato linguístico, em oposição ao esquema pontual de sua localização, permite explicar as afasias como a manifestação de um estado anterior no percurso do aprendizado da fala. Freud argumenta que se a incapacidade de falar estivesse de fato associada a uma lesão localizável em certa parte determinada do córtex, não haveria explicação para aqueles afásicos que continuam a reproduzir certas expressões, mesmo depois de haver perdido sua capacidade de falar. Tal explicação só se torna plausível para Freud por uma abordagem não mais fisiológica, mas funcional dos distúrbios linguísticos, como enfatiza Heller-Roazen. Estas produções atípicas de linguagem, que retornam ao idioma depauperado do afásico e que emergem do tempo em que ainda possuíam as competências de fala, consubstanciam para Freud uma matéria resistente, produzida em um instante de grande excitação psíquica, cuja intensidade é responsável pela inscrição posterior destas expressões na situação do mutismo. Freud oferece diversos exemplos destas inscrições linguísticas anacrônicas e deslocadas, a que chama de Sprachreste, "restos de língua". Ele cita pacientes que possuíam apenas a capacidade de pronunciar uma forte interjeição, como a maldição em língua estrangeira "Goddam", ou aqueles que repetiam porções mais extensas de conversas que tivessem sido decisivas na vida dos pacientes antes de mergulharem no silêncio. Menciona o caso de um copista, que sofreu um derrame "depois de laboriosamente completar um catálogo" (FREUD apud HELLER-ROAZEN, 2010, p.118). A única frase que conseguia dizer depois do derrame era "lista completa". Qualquer semelhança com o personagem Bartleby de Herman Melville não deverá ter sido mera coincidência. 
Como observa Heller-Roazen, na elucidação destes exemplos, "o papel da tradução neste modelo de psique é claramente decisivo" (2010, p.122). A consciência surge para Freud como resultado "de um processo de estratificação, segundo o qual o material presente na forma de vestígios de memória é sujeito, de tempos em tempos, a um rearranjo de acordo com as circunstâncias novas, a uma retranscrição" (FREUD apud HELLER-ROAZEN, 2010 p.120). A consciência surge de maneira gradual, como processo de escrita e reescrita múltiplas, pelos quais os signos que representam nossas percepções vão sendo fixados e revistos continuamente. Cada uma destas retranscrições acontece num tempo diferente e entre dois registros ou ocorrências de memória haverá necessariamente falhas, que podem ser preenchidas ou apagadas por formas posteriores de escrita, como sublinha Heller-Roazen a partir de Freud. Übersetzungen é a palavra que Freud utiliza em carta a seu amigo Fliess, para esclarecer a ele o que está em jogo em sua teoria sobre a afasia. Heller-Roazen recupera trechos desta carta para sublinhar o papel vital da tradução no pensamento freudiano acerca do funcionamento do aparelho psíquico. Em sua análise desta carta, o pesquisador norte-americano destaca o trecho em que a expressão "fracasso de tradução" comparece decisivamente para nomear os momentos em que não é possível equalizar as rupturas entre as diversas inscrições na psique, provocando a aparição de anacronismos. Uma parte do material psíquico deixa de ser transferido para a nova inscrição, com conseqüências por vezes severas para o indivíduo em questão, posto que cada inscrição posterior teria a função de inibir a anterior e de lhe retirar o processo de excitação responsável por sua geração. Um fracasso de tradução interrompe este processo de reinscrição contínua de memórias, ocasionando a repressão daquele material que deveria reaparecer sob novo registro em nova temporalidade.

Heller-Roazen conclui que na teoria freudiana a mente funciona de modo salutar apenas enquanto duram os processos de tradução e a mente paralisa em estado de "repressão", toda vez que uma ins- 
crição não consegue ser vertida em outra. Os restos de língua que os afásicos manifestam marcariam, assim, uma espécie de "ponto limítrofe" neste processo de reescrita contínua que define o mecanismo psíquico para Freud, precisamente aquilo que resiste a qualquer revisão, algo que não pode ser alterado ou dito de outra forma, porque é testemunho de uma capacidade lingüística já extinta. Algo "sobra" daquela habilidade anterior de rearranjar os signos, e esta sobra atesta um passado que não tolera mais tradução.

Neste ponto, Heller-Roazen propõe uma leitura surpreendente na recuperação cuidadosa que faz do texto freudiano, sugerindo que a afasia não representaria para Freud um esquecimento, mas "uma forma aguda de rememoração, na qual os indivíduos, incapazes de re-transcrever os signos de suas percepções anteriores, se lembram, por assim dizer, demais, ficando condenados à recorrência perpétua de um só enunciado à custa de todos os outros" (2010, p.123). Heller-Roazen, desta forma, aproxima os afásicos aos histéricos, estudados por Freud e Breuer dois anos mais tarde nos Estudos sobre a histeria: ambas as patologias sofrem de excesso de reminiscências. Os afásicos "exibem todos os sinais de estar assombrados por aquilo que outrora percebiam e eram capazes de enunciar; parecem estar ligados, em seu triste silêncio, a um passado que não admite tradução alguma [...]" (HELLER-ROAZEN, 2010, p.123). Seus fragmentos de fala anacrônica funcionam como testemunhos de uma capacidade linguística perdida. Isto significa que eles não esqueceram os ruídos da infância e a antiga falta de habilidade para a fala articulada. A hipótese mais vigorosa que Heller-Roazen deriva de sua investida na obra de Freud é a de que a memória prodigiosa destes indivíduos afásicos se estenderia à idade do balbucio infantil de onde emerge toda a atividade linguística: "Silencioso, o afásico seria a testemunha obstinada daquilo que nunca foi escrito e que não poderia ser dito" (HELLER-ROAZEN, 2010, p.123). Sua mudez atestaria um estado anterior ao advento das línguas articuladas.

Neste sentido, poderíamos pensar o afásico também como uma testemunha obstinada da própria infância e de sua aderência a uma espécie de texto imemorial e inesquecível, feito de todos os sons 
da língua, um texto irredutível à tradução, porque anterior ao surgimento do sujeito falante, da consciência, e de todos os idiomas humanos em particular, de onde e para onde os signos poderiam ser transpostos. O afásico e o infante, portanto, como testemunhas potentes daquilo que não se traduz. Paradoxalmente, a prática da tradução parece ser a única via de acesso a esta região infante da língua e da consciência, já que para Freud o mecanismo da psique, atrelado à aquisição da linguagem, surge e se forma da própria atividade tradutória e de processos sucessivos de retranscrições de signos. Assim, a tradução propicia a passagem de um a outro estado.

Como bem nota Heller-Roazen, há uma aporia conceitual na formulação freudiana sobre o surgimento da vida psíquica por meio de operações tradutórias, pois neste estágio anterior ao advento da fala e da subjetividade, faltariam ainda todos os componentes que habilitariam a tarefa da tradução: falta um tradutor propriamente dito, uma vez que a consciência ainda não surgiu, falta um "texto original", ainda não destacável do balbucio babélico da infância, e faltam todas as línguas diferenciais para onde os signos de um idioma em particular pudessem ser transpostos.

É precisamente este ponto cego da experiência da aquisição da linguagem e da constituição da subjetividade aquilo que a palavra tradução ajuda a nomear, a partir de sua própria inadequação, quando convocada por Freud a participar desta cena inominável, porque na antecâmera imaginária da linguagem e do humano. Em última análise, o objetivo destas considerações iniciais acerca do pensamento freudiano sobre a afasia, pela mediação de Heller-Roazen, é reivindicar que o espaço discursivo em que se enuncia o fracasso da tradução é também o espaço possível de nomeação da infância, se pensada como experiência liminar entre a ausência e a eclosão da linguagem. Pois como escrever a infância, transpor em linguagem o balbucio, encontrar entre estes polos alguns corredores de passagem, senão com as ferramentas da tradução, enfrentando suas aporias? 


\section{As meninas de Balthus}

É exatamente o que faz "em voz alta" o narrador do conto de Sergio Sant'Anna (2003), "Contemplando as meninas de Balthus": discorre sobre impasses tradutórios à medida que testa aproximações entre os universos verbal e pictórico, alinhando-se à longa tradição da ekphrasis em que se confronta o problema de escrever na presença do visível. O que é particularmente interessante neste conto de Sant'Anna é o grau de adensamento deste problema, já que a questão que assola o narrador é como frasear aquilo que é duplamente "mudo", ou seja, a mudez da tela, sua dimensão não verbal, e também a mudez da infância, multiplicada na série de meninas retratadas nos quadros do pintor franco-polonês Balthasar Balthus? A escrita de Sant'Anna se esforça por atravessar estas camadas espessas de silêncio pela exposição verborrágica das dificuldades de escrever as meninas pintadas em tinta, gerando um texto de alta voltagem metalingüística. Cito o trecho inicial do conto:

Dizer que são lascivas as meninas nos quadros de Balthus seria certamente uma impropriedade, porque a lascívia se abrigará antes no olhar que as contempla que nos corpos contemplados. Languidez, possivelmente, não seria impróprio, embora, tanto quanto a lascívia, se trate de uma palavra de baixa e ambígua definição no dicionário. Mas ambas as palavras foram aqui inscritas por sua materialidade quase carnal, sua sugestão de voluptuosidade, essa outra palavra plena de curvas e arabescos sonoros - e ela, sim, talvez aplicável às meninas de Balthus.

Mas não parecem mostrar-se conscientes ou despertas (embora, algumas vezes curiosas), as meninas de Balthus, para a volúpia que possam acender, com exceção, talvez, à primeira vista, daquela que se mira no espelhinho de mão em Le beaux jours. Mas se somos tentados a distinguir em seu olhar prazeroso e no sorriso que mal chega a se desenhar a malícia de uma inocência à beira de ruir, logo nos cor- 
rigimos para ver ali apenas um jogo infantil; feminino, mas infantil. (SANT'ANNA, 2003, p.236)

Sant'Anna se alinha aqui à tradição da ekphrasis, sobretudo aquela forjada a partir do século XVIII, e que tem na escrita de Diderot, em seu célebre ensaio sobre a pintura de Jean-Baptiste Greuze "Jovem Menina Chorando Sobre Seu Pássaro Morto" (Cf. SHAPIRO, 2007), um modelo eloquente de incorporação no texto da consciência de que as descrições devem funcionar na ausência da imagem. Ao invés de superestimar o poder da palavra e a capacidade da linguagem em apresentar o visível, escolhe-se incorporar a ausência constitutiva da imagem plástica no tecido verbal e reconhecer os limites da empreitada tradutória através de recursos da ironia e da multiplicação de perspectivas e modos de subjetivação. Substitui-se a voz autoritária e monológica de um narrador confiante no poder do verbo, por narrativas polifônicas, construídas sob a forma de especulação filosófica, que engajam o leitor na partilha das dificuldades de representação, conforme observou o pesquisador norte-americano Gary Shapiro (2007), em contexto diverso, em seu ensaio "The Absent Image: Ekphrasis and the Infinite Relation of Translation".

Notem que o narrador utiliza a primeira pessoa do plural num movimento estratégico de inclusão do leitor, possivelmente masculino, neste duplo impulso de virilizar a cena observada e de desqualificar prontamente este mesmo gesto. Notem ainda que ao trocar a malícia pela inocência, a substituição não se faz de modo definitivo a ponto de apagar inteiramente a voluptuosidade sugerida. Resta desta operação de rasura daquilo que na infância é pressentido, enunciado e logo descartado e substituído, uma sobra de sentido ao modo do que Freud chama de Sprachreste - algo é arrastado de um ponto a outro e este gesto força uma abertura e uma passagem entre os dois termos, malícia e inocência. $\mathrm{O}$ ato de dizer, desdizer e redizer a natureza da infância no quadro expõe e potencializa uma "relação infinita" entre o que se vê e o que se diz. Retomando Foucault em seu conhecido ensaio sobre "Las meninas" de Velás- 
quez, "[...] por mais que se diga o que se vê, o que se vê não se aloja jamais no que se diz, e por mais que se faça ver o que se está dizendo por imagens, metáforas, comparações, o lugar onde estas resplandecem não é aquele que os olhos descortinam, mas aquele que as sucessões de sintaxe definem" (FOUCAULT, 2011, p.12).

Sant'Anna não perde jamais de vista o reconhecimento desta proposição e trabalha para manter aberta a relação entre o dizível e o visível a partir justamente de suas incompatibilidades. Trata-se de uma questão de lógica. Se o que há em comum entre palavra e imagem é o fato de serem linguagens irredutíveis uma a outra, a melhor maneira de permanecer fiel a esta relação é ressaltar continuamente entre elas este gap ou écart, como diz Foucault. Daí o empenho metalingüístico em destacar a materialidade exuberante das palavras, tornada tão mais palpável e atual pelas tentativas frustradas de transposição do visível no dizível.

O verbo "dizer" que abre a narrativa - "dizer que são lascivas as meninas nos quadros de Balthus" - explicita desde logo o território da escrita e de seus materiais, profusamente presentes e encarnados em diversos dispositivos de linguagem. Observe-se a recorrência dos modais - certamente; possivelmente; talvez; parecem - que são instâncias próprias do discurso verbal, cuja função aqui é marcar a atitude especulativa do narrador frente ao narrado, não havendo transposição adequada desta marca subjetiva para o universo pictórico. Além dos modais, a escrita chama a atenção para seus componentes discursivos, para a justeza ou impropriedade das palavras empregadas para descrever os quadros. O ponto alto desta estratégia de atualização do mundo verbal se dá na porção final do primeiro parágrafo, em que a palavra "voluptuosidade" é apresentada como signo plástico, numa tentativa sinestésica de condensação de materiais advindos de universos distintos.

Todo o conto potencializa este microesquema inicial. A cada novo parágrafo, descreve-se uma nova tela por meio de aproximações e distanciamentos entre os campos do dizível e do visível. Este regime de paragrafação é acentuado por expressivas pausas gráficas entre um e outro bloco discursivo, o que ajuda a simular 
a sensação de que estamos diante de uma série de quadros autônomos, ou seja, o plano verbal incorpora uma forte dimensão de visualidade, gerando enquadramentos muito bem delineados de cada uma das cenas pictóricas descritas. E, no interior de cada parágrafo, é possível flagrar este mesmo impulso em direção à contaminação do dizível pelo visível e vice-versa. O horizonte utópico desta meditação paciente, quadro a quadro, parágrafo a parágrafo, é de fato a conversão alquímica das palavras em imagens e das imagens em palavras, algo que se diz com grande força expressiva no filme documentário "Lixo Extraordinário" (2011), codirigido por Lucy Walker, João Jardim e Karen Harley. Ali há uma cena curiosa em que o artista plástico brasileiro Vik Muniz emula para catadores de lixo do Aterro Sanitário de Gramacho as movimentações e posturas convencionais dos visitantes de museus. Muniz olha o quadro de longe, depois se aproxima mais da tela, volta a se afastar, se aproxima novamente, se afasta. Em movimentos pendulares, tal qual um João Bobo, o artista vai e vem, provocando riso nos catadores de lixo e na plateia do cinema. Muniz explica: quando o espectador se aproxima da tela, ele vê os materiais (a tela, a tinta, a cor, a textura, a pincelada), quando se afasta ele vê a imagem, a paisagem, as formas. A experiência da arte acontece, segue Muniz, quando uma coisa se transforma em outra. É preciso ir e vir para tentar capturar o instante fugidio que ele chama de "momento mágico", quando os materiais se transformam numa imagem, prestes a se dissolver em matéria.

A presença da infância nos quadros de Balthus parece favorecer a emergência deste momento alquímico, já que as meninas surgem diante do narrador como figuras-testemunhas deste outro tempo imemorial, anterior à diferenciação das línguas e à demarcação rigorosa dos campos disciplinares da literatura e da pintura, lá onde se agita indiscriminadamente sempre mais de um.

Podemos então perceber a ocorrência simultânea da possibilidade erótica e inocência, captadas talvez em seu último momento de conjunção, no olhar vago e introspectivo da 
menina e no seu corpo disposto em oferenda imaculável, dádiva e negação. Eis aí uma das faces da esfinge, que podemos apontar, sem com isso pretender ter decifrado inteiro o seu enigma, que continuará a nos desafiar, nesta e noutras obras de Balthus. Algo que estará na representação da realidade mesma, mas também além dela, inalcançável, a não ser através da própria pintura solenemente silenciosa do Conde Balthazar [...]. (SANT'ANNA, 2003, p.238-239)

A infância como manifestação do informe, daquilo que é impossível contornar precisamente porque excede e borra todos os contornos, torna-se figura estratégica para uma espécie de entoação fabular da tradução. Dito de outra forma, a tradução comparece aqui como ficção de um método incisivo de escrita que por teimosia e persistência, em linguagem meticulosa e repetitiva, faz uma aposta alta no pensamento em fronteira, "aquele que na linha e na obstrução propicia aberturas” (HISSA, 2011, p. 14).

Deixo a palavra final com o narrador do conto:

Escrever. Se nos ensinam alguns mestres que a atitude mais sábia diante das pinturas raras, como as de Balthus, irredutíveis a outra forma de expressão, é a do "contemplar atento e silencioso", como diz Jean Leymarie, por que cometeríamos aqui essa transgressão?

É que, contemplando as meninas de Balthus, somos às vezes acometidos pela exasperação do amor e do desejo por tanta beleza, na qual não podemos nem devemos tocar. Então, insensatamente, é como se quiséssemos estar no quarto com Kátia lendo ou Thérèse sonhando ou nos quartos de todas elas, encantados em um pássaro de brinquedo, uma meia, um gato, um colar. Ou, ainda, travestidos em palavras, com a fome desesperada de que, como no sítio mais sombreado de Les beaux jours ou através da cortina aberta de um golpe em La chambre, estas palavras sejam fogo e luz. (SANT'ANNA, 2003, p. 246) 


\section{Referências}

AGAMBEN, Giorgio. Infância e História: destruição da experiência e da origem da história. Trad. Henrique Burigo. Belo Horizonte: UFMG, 2005.

FOUCAULT, Michel (1966). Las Meninas. In: . As palavras e as coisas. Tradução Salma Tannus Muchail. São Paulo: Martins Fonte, 2011. p. 3-21.

FREUD, Sigmund (1891). A interpretação das afasias. Tradução António Pinto Ribeiro. Lisboa: Edições 70, 2003.

HELLER-ROAZEN, Daniel. Ecolalias: sobre o esquecimento das línguas. Tradução Fabio Ackelrud Durão. Campinas: Editora da Unicamp, 2010.

HISSA, Cássio E. Viana (Org.). Conversações. De artes e de ciências. Belo Horizonte: Editora UFMG, 2011.

LIXO EXTRAORDINÁRIO [Filme-vídeo]. Direção de Karen Harley; João Jardim; Lucy Walker. Produção de Almega Projects e O2 Filmes. 2011. 1 DVD (99 min), Color.

SANT'ANNA, Sérgio. Contemplando as meninas de Balthus. In: . O voo da madrugada. São Paulo: Companhia das Letras, 2003. p. 236-247.

SHAPIRO, Gary. The Absent Image: Ekphrasis and the "Infinite Relation" of Translation. Journal of Visual Culture, v. 6(1). Los Angeles, London, New Delhi and Singapore: SAGE Publications, 2007. p. 13-24.

Recebido em: 12/02/2014 Aceito em: 23/05/2014 